\title{
Android App for Improvising Sign Language Communication in English and Hausa
}

\author{
Bulus P. Bala \& Laminu Aminu Song \\ Department of Computer Science \\ Federal College of Education, Yola Nigeria
}

\begin{abstract}
Deaf and dumb persons are facing great challenges communicating with people in society despite the fact that they are part of the society and are enrolled in the normal school system where teaching and learning take place using spoken language. This challenge calls for the need to address the problem of communication through the use of mobile technology. Developing a mobile app to enhance learning and communication is of great importance and thus the focus of this paper. Obviously most of the applications available were developed using foreign languages which is not easy to use. In this paper, we introduce the Simple Sign Language Translator Application (SSLATA) that will help people to learn and master sign language. The introduced application will translate words from sign language to English or Hausa languages, text to speech to sign, speech to text to sign and vice-visa. The SSLATA through its user-friendly interface will enable users to interact with one another via either spoken language or sign language. Constructive research approach and an agile model were adopted for the study. Android Studio, SQLite and Java were the environment and language used in developing the app. The application runs on android operating system devices.
\end{abstract}

Keywords: Sign Language, Mobile Phone App, Android System.

\section{INTRODUCTION}

Deaf and dumb is a term means a person who could neither hear nor speak or both. Many deaf and dumb persons are enrolled in a school system where learning takes place in a conventional way. They put effort to learn how to read and write using the traditional method of learning in addition to sign language which most of them understood well which most people without hearing impairment do not do. However, despite these efforts, communication between people with hearing impairment and those without is extremely difficult especially in a classroom that joins these people together. These class of people will have difficulty in making friends with their core students and even teachers either within or outside the school environment because of the communication barrier.

School for adult, special and none formal education, is established to take care of people with special needs. Most of it students are without any impairment and they need to learn and master among other things sign language and sign language communication. There are no enough experts to handle this area of study [1]. Thus, the quest for developing an Android App for Improvising Sign Language communication.

\subsection{Sign Language}

Sign language is a language in which sign is used to act as a word. The origin of sign language can be traced back to the Greek philosopher Socrates who lived in 469-359 B.C. He weighed up how people could communicate if they were not having voice and tongue. Sign Language is a language that dictionaries cannot be consulted when checking the definitions of signs, origin of sign, as one would use the English dictionaries instead; Sign Language dictionaries are guided on how to sign a word written in English [2]. Sign language is a system of using manual-general sign as a medium of communication by the members of a given community [3]. Sign language is used in deaf community where sign is use in communication everywhere in the world. According to [4], sign language is the use of symbols while communicating.

Sign language is a language developed in a deaf-dumb communities, which could include interpreters, families and friends as well as people who are deaf or hard of hearing at all themselves [5]. It is a language which instead of acoustic, convey sound 

orientation and movement of hands, arm or body and facial.

Though sign language is predominantly used by deaf-dumb persons, it is actual a language for every one whether deaf-dumb persons or persons without hearing problem because sign language do not represent spoken language. According to [6], sign language it is independent of surrounding spoken language but equal in status with spoken language.

The stages of sign language acquisition are the same as those for spoken language. According to [6], Babies start by "babbling" with their hands. When they first start producing words, they substitute easier handshapes for more difficult ones, making for cute "baby pronunciations." They start making sentences by stringing signs together and only later get control of all the grammatical rules. People can learn through natural interaction with the people around them.

\subsection{Mobile Phone Application (app) in Learning}

Mobile phone application are applications that run on mobile phones. This apps are developed and used for different purposes. They are mostly used on smart phones such as android, ios, tablet computers etc. Smart phones are capable of running multimedia. Multimedia here means any device or computer that mediated software or interactive application that integrates text, color, graphical images, animation, audio sound, and full motion video in a single application [7].

The importance of mobile apps in teaching and learning are so numerous. Mobile phone app if used will bridge communication among people. Some importance using mobile app as follows;

- one to learn at his/her pace

- Communicate effectively without actually understanding sign language

- One to understand deaf-dumb around better and vice-versa

- Can be used any and any time

- People who develop this problem in at any stage in life can easily learn.

\section{Statement of the problem}

Persons without hearing impairment do not naturally used hand gesture as a medium of communication but for demonstration where need be. People learning deaf-dumb ways of communication have some difficulties in learning sign language. They therefore need to learn basic language skills before they can communicate effectively with deaf-dumb persons not to mention teaching language. Such persons have some common language barrier. This barrier include difficulties in expression, asking and answering questions and inability to catch up with complete conversation with the deaf-dumb. These problems of communication in sign language encountered by those aspiring to learn and specialize in deaf-dumb communication is a serious challenge that need to be tackled by developing an application that will help minimize this challenge through improvisation and in communication.

\subsection{Andriod System Brief Overview}

Android is a relatively new platform. It is produced by Google, Inc., and its first release was presented in 2007 [8]. Android is installed on many different mobile devices and its users can download Android apps and other content through Google Play service, which replaced the old Android Market [9]. As the official Android website describes this platform, "Android is a software stack for mobile devices that includes an operating system, middleware and key applications" [10]. Android provides the "core set of applications including an email client, SMS program, calendar, maps, browser, contacts, and others" [10], while additional applications can be downloaded through Google Play service [9]. Google (n.d.) claims that "Android powers millions of phones, tablets and other devices." Phones and tablets are mobile devices that can have Android applications installed on them.

\subsection{Related work on Mobile Phone App for Deaf Persons}

Mobile phones Technology aids in providing educational opportunities in the education of deaf-dumb persons who struggle with conventional education methods of teaching and learning. The increase in availability of smart Mobile phones devices and their support for Internet enabled functionalities have made them a great tools for use by all people. The use of mobile devices has considerably grown in society and is contributing to the individual, as well as collaborative, learning of deaf students [11].

This section, discussed some of the applications that were developed for communication, teaching and learning sign language (SL).Deaf persons are facing difficulties in communicating with other persons in the society and those enrolled in the school system, are not finding it easy either.

There are few mobile applications for Deaf and dumb like Deaf and Dumb through 3G applications [12]. These techniques only enable communication between deaf and dumb through sign language using mobile phones. The mobile application which 
International Journal of Advances in Scientific Research and Engineering (ijasre), Vol 6 (2), February-2020

proposed by [13] helps to make recognition of sign language. Mobile-based Deaf and Dumb Interaction System project by [14], proposed mobile application that enables the needs of 'deaf and dumb developing a voice-activated mobile which would convert their sign language into messages that may be read by other users, this message can also converted to a voice. Mobile-based Deaf and Dumb Interaction System project by [12], enables deaf-dumb people to translate sign language letters to English and Arabic and vice-versa. [1], came up with multimedia education system, an education application system designed for children from age 35 to help in learning sign language through multimedia to understand basic of English and Math. An MSL-based mobile application was developed to assist the deaf respondent with learning the basic English alphabet in MSL at both school and home [1]. This application provided the signs, picture and video clips for learning. Sixty-six percent of respondents were satisfied with the visual content of the application. Another mobile application was developed to learn and practice BSL by incorporating a feedback process [15]. In this application, different learning exercises were provided in which Hearing Impaired (HI) learners physically reproduced the signs and got the feedback of their gestures. [16], proposed an architectural framework based on PSL using information technology. In this framework, all the standard gestures and grammatical rules of PSL were presented to convert English/Urdu text into PSL. This framework helped to identify the important components to develop an application for the deaf community of Pakistan. It also helped to fill the communication gap between hearing and deaf people. [17], the learning of alphabet signs was provided in MSL and BSL. [15], applications were developed to assist deaf students to learn alphabets and numbers. [18] only focused on helping deaf students to learn numbers. [19], provided the assistance for improving reading skills and for learning the signs of objects of daily use.

Most of the studies mentioned in this section replicated learning in ASL, LGP, BSL, and MSL that had signs/symbols different from that of NSL. It is also observed, they mostly only focused on English alphabet and numbers learning. Therefore, there is a need to develop an application that provides basic for improvising communication in sign language within and out of school environment. This study introduced android application that will enable user to learn common words, days of the week, colors, members of the families etc in addition to learning English alphabet and numbers. It will translate words from sign language to English or Hausa languages, text to speech to sign, speech to text to sign and vice-visa. The app through it user friendly interface will enables user to interact with one another via either spoken language or sign language.

\section{System research approach, implementation and advantage}

\subsection{Research approach}

The research approach that this study adopted was constructive research. It is a form of scientific knowledge production that involves the development of innovative constructions, intended to solve problems confronted in the real world, and simultaneously makes a prescriptive scientific contribution [20].The main objective of the constructive research is to recognize and find solutions to problems confronting mankind. The identified problems are used to propose solutions that will address the problem by constructing a solution which will be operationalized to determine its workability and appropriateness [21]. Therefore, the constructive research is selected for this study as the most acceptable choice for the development of a mobile application. The underlying problem in this case is barrier in communication between deaf-dumb person and with persons without hearing impaired.

Agile model was adopted for this application due to it very simplicity to understand and use. It does not build an entire system at once, but rather develops incrementally, a review take place to determine if the project is on the right track.

\subsection{Program Data Flow Diagram of the application}

Figure 1.1 show Data Flow Diagram of the application. It depicted diagrammatically, steps followed to develop the Text to Sign language conversion segment of the application. Figure 1.2 depicted diagrammatically, steps followed to develop the Voice to text, text to sign language conversion segment of application. 


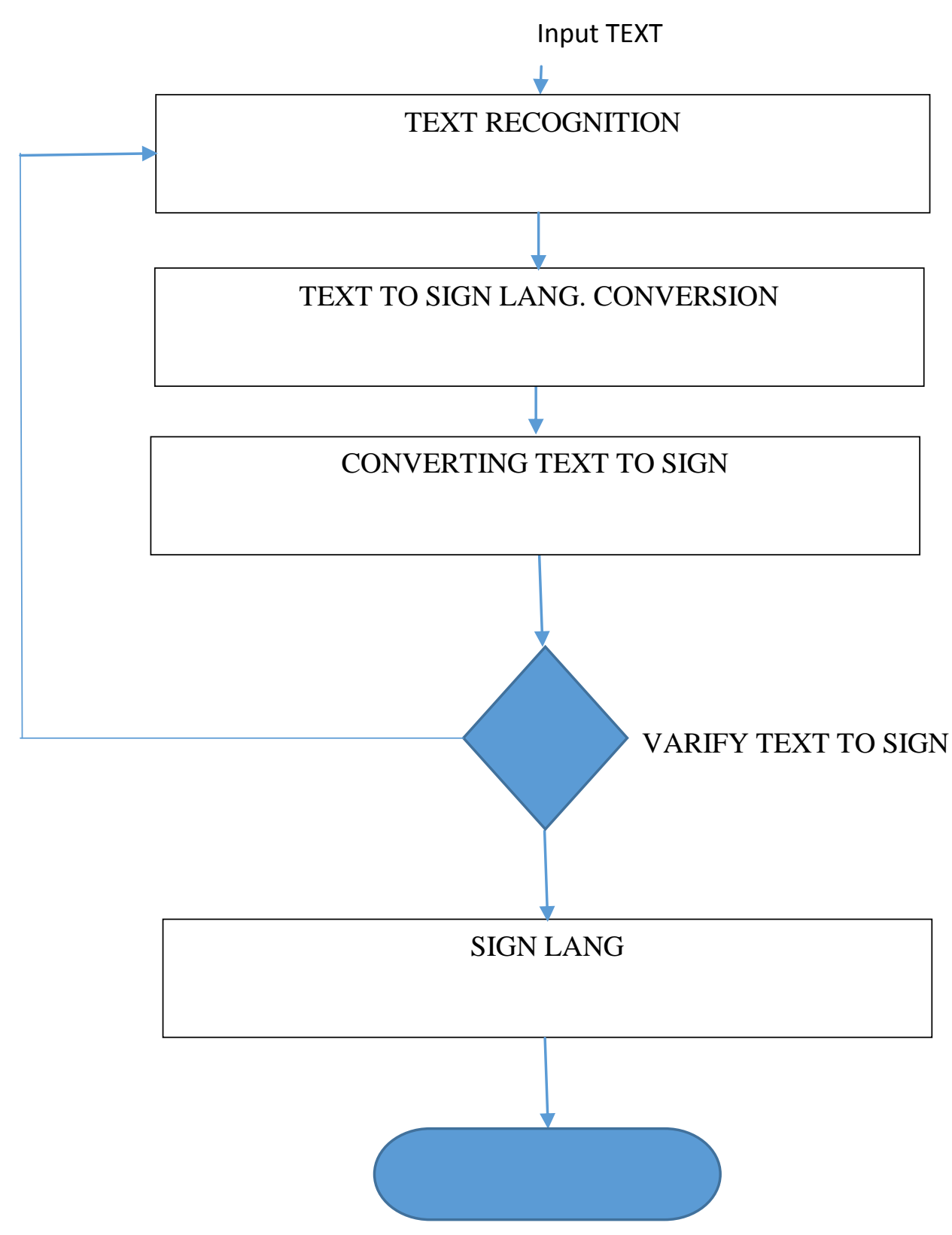

FIG 1.1: TEXT TO SIGN LANGUAGE CONVERSION DATA FLOW DIAGRAM 


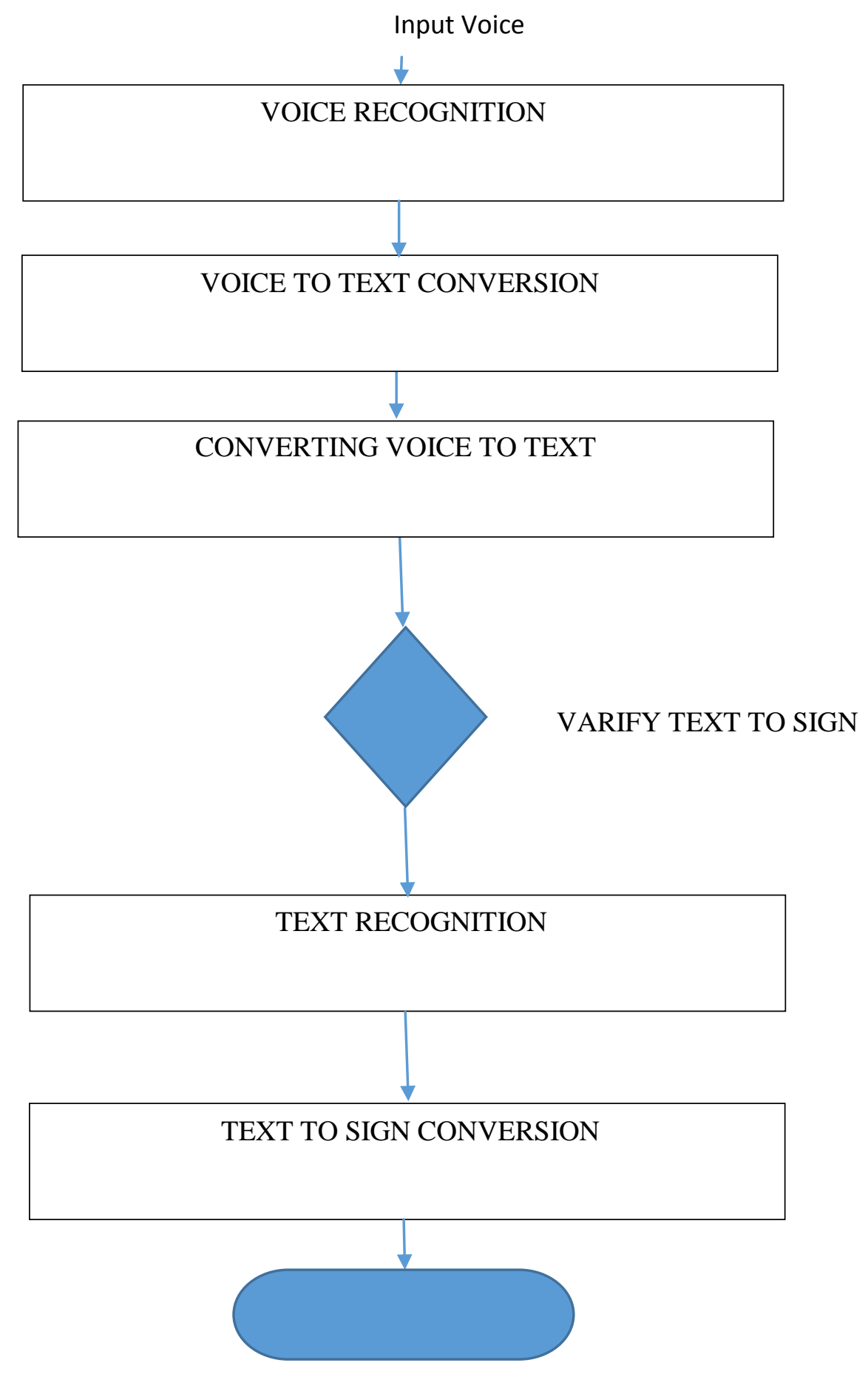

FIG 1.2: VOICE TO TEXT TO SIGN LANGUAGE CONVERTION DATA FLOW DIAGRAM

\subsection{Java (Android version) and Tools}

"Android is a software stack for mobile devices that includes an operating system, middleware and key applications" [10]. "Android powers millions of phones, tablets and other devices." Phones and tablets are mobile devices that can have Android applications installed on them. This study used Java programming language (Android version).

Java is a computer programming language that was developed by James Gosling at sun Micro system and released in 1995. The choice for Java in this study is because android use java programming language, in cooperated in android studio. It is plat form independent and flexible in nature. The most significant feature of java is to run a program easily from one computer to another. 
International Journal of Advances in Scientific Research and Engineering (ijasre), Vol 6 (2), February-2020

Extensible Markup Language (XML) is used to describe data. The XML standard is a flexible way to create information formats and electronically share structured data via the public Internet. Android application development include setting up Android development environment on the machine, AndroidManifest.xml file, Activities, Intents, and XML layouts.

Manifest is the root element of the AndroidManifest.xml file. It has package attribute that describes the package name of the activity class.

AndroidManifest.xml is one of the most important files in the entire study, providing essential information to the Android build tools, the Android operating system [24]. Manifest is very important because if it is not setup properly, then the application will have problems such that Android system will not be able to locate all of your Activities and Services.

\subsection{Implementation}

The end result of the research is to have an efficient app for people to use in learning sign language. The app usage will involves series of step. It first involves launching the app. After successful launching the app and displayed. There are two language options; English and Hausa. Language selection can help to choose different language sections. The learning sections include alphabets, common words, numbers colors days of the week, and members of the family etc as shown below;

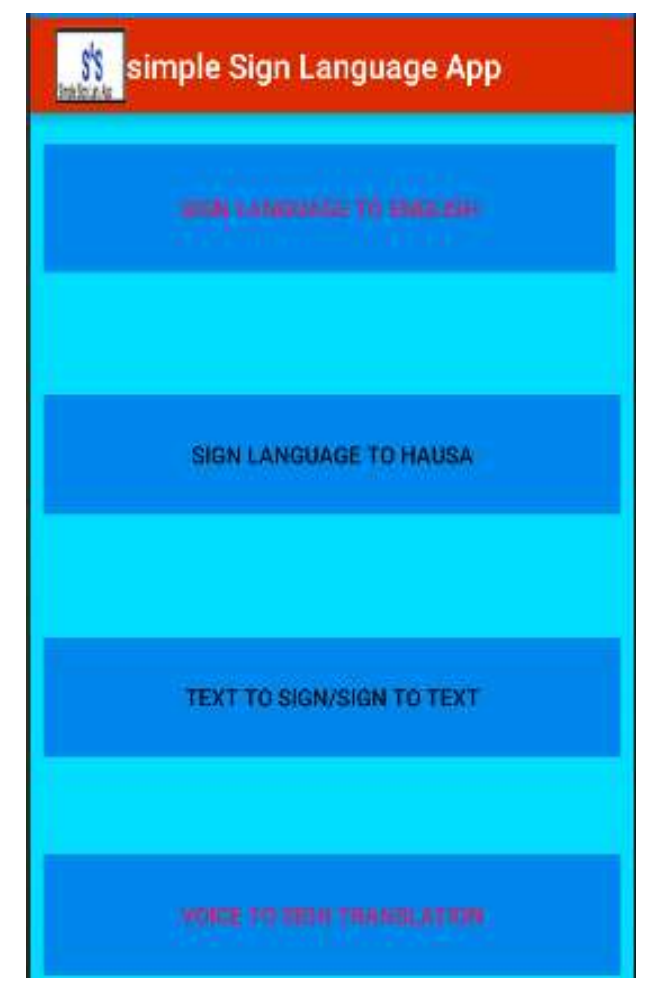

Fig2: Home Screen

Fig2 represent the home page of the application. This page allows user to enter the different sections of the application. 
International Journal of Advances in Scientific Research and Engineering (ijasre), Vol 6 (2), February-2020

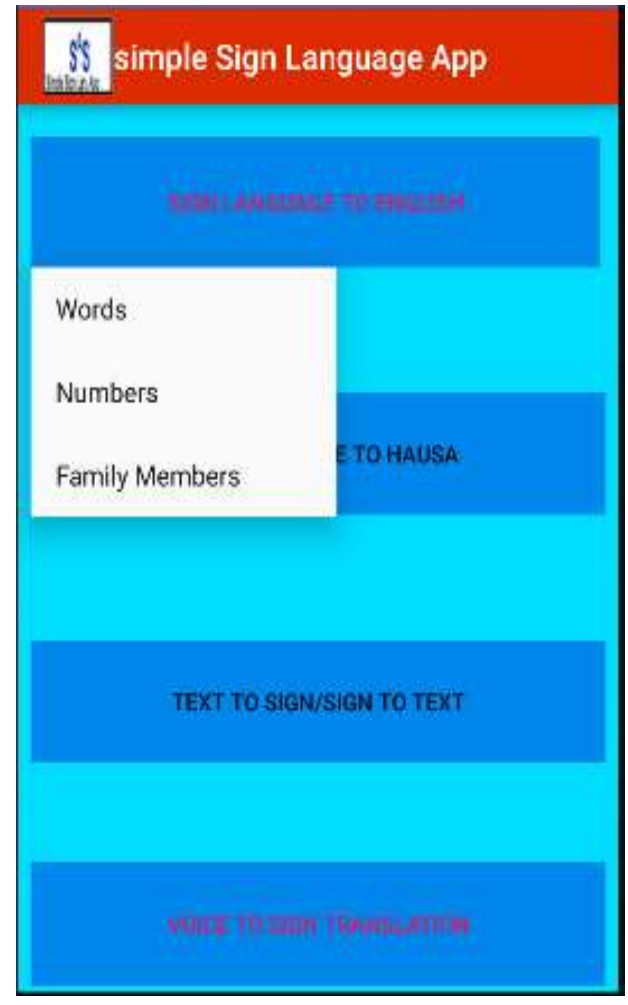

Fig3.0: Sign Language To English

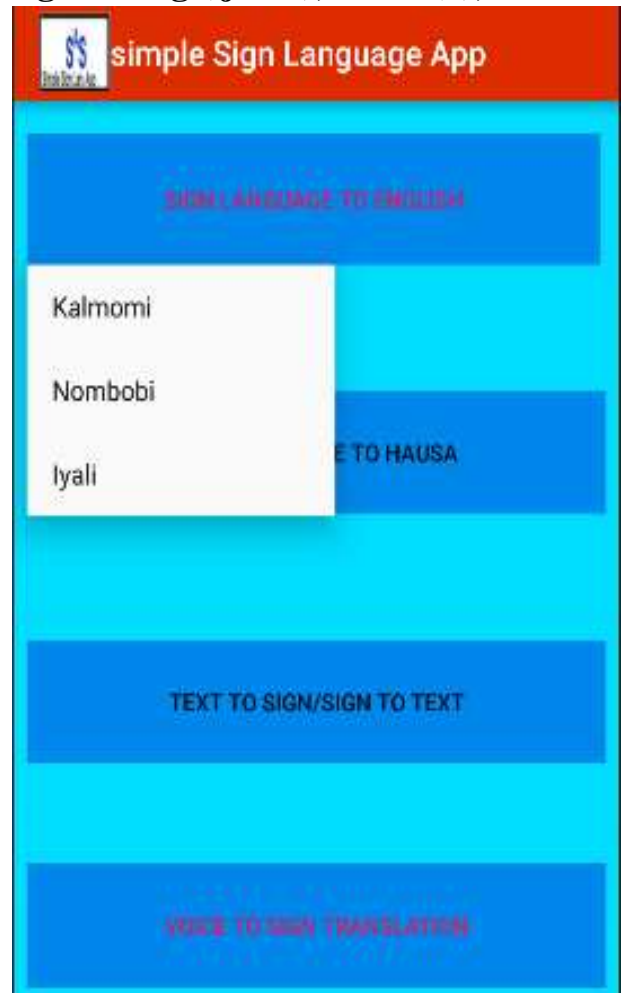

Fig3.1 Sign Language To Hausa

The sign language to English menu has a submenu likewise sign language to Hausa. When a user select "SIGN LANGUAGE TO ENGLISH" or "SIGN LANGUAGE TO HAUSA" from the menu, the submenu will be displayed as shown on fig3.0 and fig3.1 respectively.

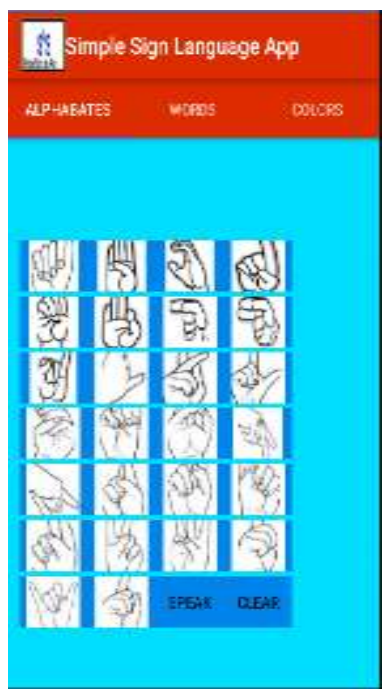

Fig4.0: Alphabets

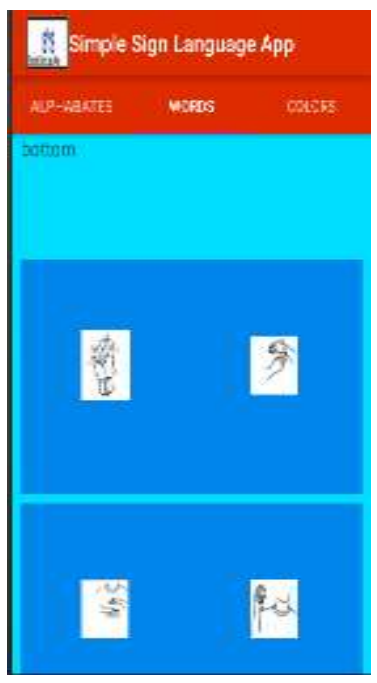

Fig4.1: Words

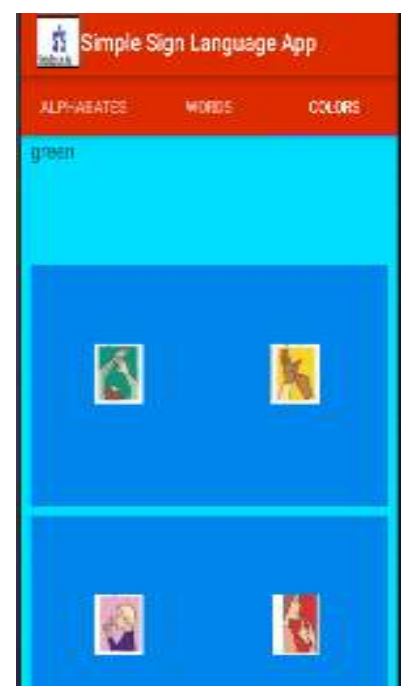

Fig4.2: Colors

The "words" submenu of the application has alphabet (sign language keyboard) tab, words tab and colors tab. "Kalmomi" submenu of the application" has Lettoti (keyboard na kurame) tab, Kalmomi tab and Kala tab in English and Hausa respectively. Both has similar interface layout. When a user choose a tab from the categories of tabs, what is under it will be displayed as shown in fig4.0, Fig.4.1 and Fig.4.2 respectively.

Alphabet tab contain sign language keyboard with sign alphabet in English and Hausa. The Keyboard translates any letter from sign language to English or Hausa and vice versa. Words tab will display common words that hearing impaired persons used that people without hearing impairments can learn easily. Color tab display colors which can be translated into English or Hausa. 
International Journal of Advances in Scientific Research and Engineering (ijasre), Vol 6 (2), February-2020

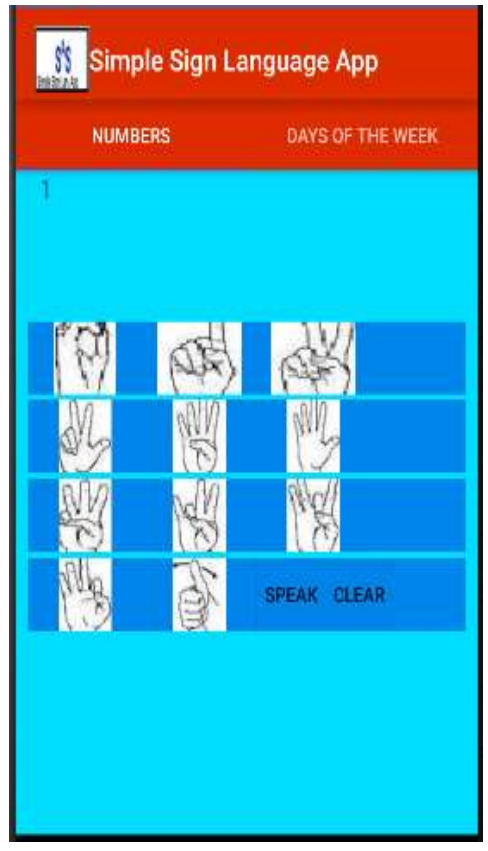

Fig5:Numbers 0-10

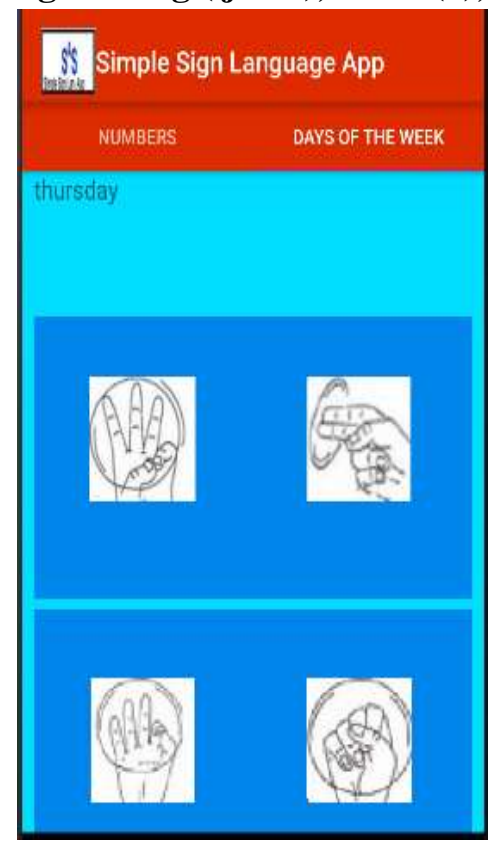

Fig5.0: Days of the Week

The "Numbers submenu of the application" has numbers (nombobi) tab and Days of the week (ranakun mako) tab respectively. When a user choose a tab, what is under it will be displayed. When a particular sign is selected from the displayed signs, the app translates the selected sign into it English or Hausa meaning as shown in fig5.

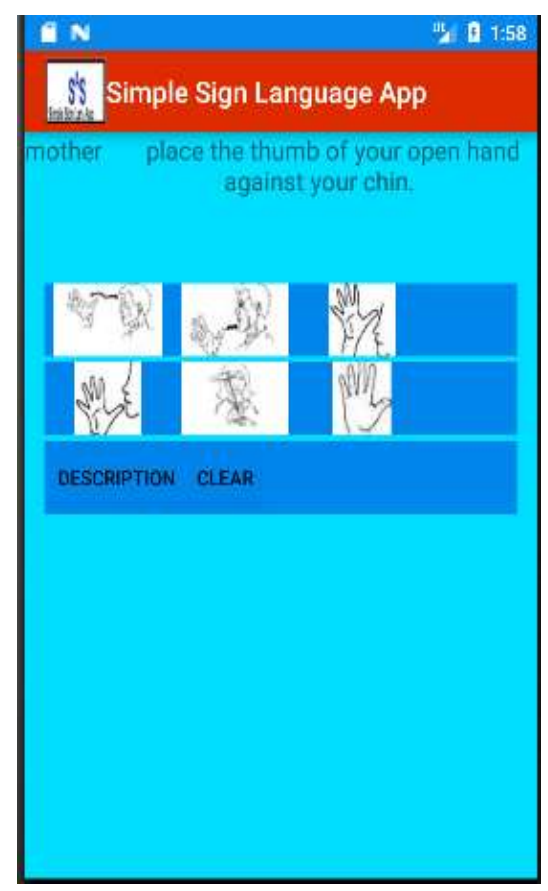

Fig6: Members of the Family

The same is applicable to Members of the family (Iyali) submenu. This submenu has only one tab; family (Iyali) member tab. It displays the nuclear and extended family members in sign language. When a user select one of the signs displayed, it English or Hausa meaning will be processed and displayed. If the user is not clear on the gesture that form the selected word, "DESCRIPTION (Bayani a Hausa)" button can be clicked. The "DESCRIPTION" button when click, display explanation on sign movement of the selected sign word and in Audio form as shown in fig6. 
International Journal of Advances in Scientific Research and Engineering (ijasre), Vol 6 (2), February-2020

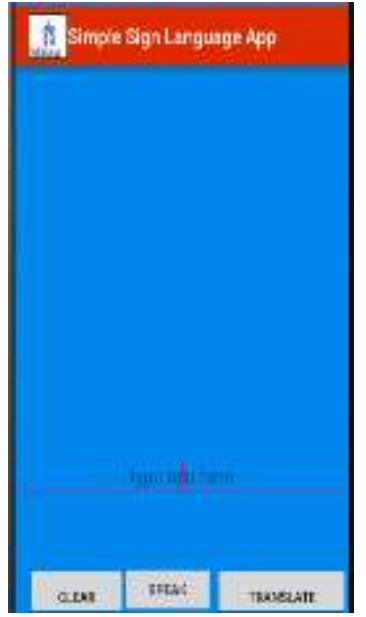

Fig7.0: Text To Sign/Sign To Text

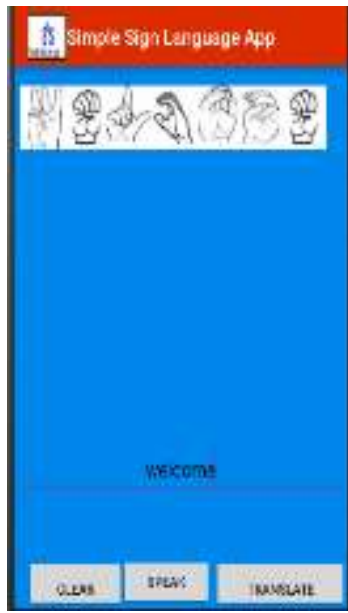

Fig7.1: Translated Word

The "TEXT TO SIGN/SIG TO TEXT" enables user to translate any letter or word in English or Hausa to sign language and vice versa. When the user select "TEXT TO SIGN/SIG TO TEXT", it opens as shown fig7.0. User can then type any word (s) either in English or Hausa in the "type text here" field. When user click "TRANSLATE", word typed in the field will be translated into sign language word(s).

User can also click and hold the "SPEAK" and speak. Ones you release your hand off the "SPEAK", whatever you say appears in the "type text here" field. You can then click "TRANSLATE", for translation into sign language as shown in fig 7.1. The "CLEAR" when click, clears the screen content.

\subsection{Advantage of the Proposed System}

The system, will help user especially students of SLD learn and master sign language at their paces through improvisation. It will help them learn sign language and ease communication with deaf-dumb persons. It will help them to learn at their pace anytime and anywhere. The apps provides platform to learn alphabets, letters in sign language, common words from sign language to English and Hausa. This will reduce drastically the difficulties in learning sign language thereby building user confidence.

\section{CONCLUSION}

This paper presents an android app for effective improvised sign language communication. The application is aimed at helping persons without hearing impairment especially students of special learning of people with disability and persons with hearing problem who are uneducated learn basic of sign language communication through improvisation. The application will enable users to chat anywhere in addition to learning sign language communication. More so, it provides user with the flexibility of translating sign language letters and words into English and Hausa and vice versa.

\section{REFERENCES}

[1] Nour E.M,Bana Y.M.T., Mohammed A. H.,(2013), Multimedia Education System for Deaf and Hear Impairment Children. International Arab Conference on Information Technology

[2] Wallin, Lule, Lutalo\& Basingya(2006).Uganda Sign Language Dictionary: Kampala; Sign $\quad$ Language Research Project Kyambogo University.

[3] KSL \&KSDC(2006):Theory and Skills of Teaching Kenyan Sign Language. Nairobi:

ISBN: 9966-

7144- $\quad 0-5$

Florence P.(2015), FACTORS INFLUENCING USE OF SIGN LANGUAGE IN TEACHING

\&LEARNING IN PUBLIC PRIMARY SCHOOL IN KIAMBU COUNTRY, KENYA. Retrieved from http://erepository.uonbi.ac.ke/bitstream/handle/11295/91131/pakata_\%20Fa

ctors \%20influencing\%20use \%20of\%20sign\%20language.pdf?sequence=1\& is Allowed=y on 19/7/2019

[5] Zeshan U. Madan M. Vasishta M. Sethna M (2004): "Implementation of Indian Sign Language in Educational settings" Volume 15, number2, Asia Pacific Dis-ability Rehabilitation Journal pp15- 35.

[6] Arika O. (2015), 7 Things You Should Know About Sign Language retrieved

$19 / 7 / 2019$

from

http://mentalfloss.com/article/13107/7-things-you- should-know-about- sign- language 
International Journal of Advances in Scientific Research and Engineering (ijasre), Vol 6 (2), February-2020

[7] Winogrid, Terry (1997), "The Design of Interaction Beyond Calculation; The Next fifty years of computing, Copernicus, Springer-Verlag ACM New York

Meier, R. (2010). Professional Android 2 Application Development. Indianapolis,

IN. Wiley

Publishing, Inc.

[9] Bishop, T. (2012, March 6). “Google Play replaces Android Market, cosolidates Google's media marketplaces”. Retrieved from http://www.geekwire.com/2012/google-playreplaces-android-market- consolidates-googles-mediamarketplaces

[10] What is Android? (2012). Retrieved October 27, 2019 from http://developer.android.com/guide/basics/what-isandroid.html

[11] Alvare z, Alarcon C, Nussbaum R.(2011). Collaborative learning activities in the classroom supported by one-to-one mobile computing A design-based process. J. Syst. Softw. 2011, 84, 1961-1976. [CrossRef]
Dalia N., ABeer S, Fowzyah A., Reem A.(2014), AN ANDROID APPLICATION
TO AID
UNEDUCATED DEAF-DUMB PEOPLE. International Journal of
science and Mobile $v$

[13] Zhao S., Wang M., Wei Z. (2013), “A New Type of Deaf-Mute Sign Language Recognition

System Based on the Mobile Communication Platform and Terminal Equipment" Advanced Materials Research. Volumes 734-737, 2880- 2886

[14] Karpov, A., Kipyatkova, I., Zelezny, M..(2006). Automatic Technologies for Processing Spoken Sign Languages. Procedia Comput. Sci. 2016, 81, pp. 201-207. [CrossRef]

[15] Sahid, A.F.B.M., Ismail, W.S.W.,Ghani, D.A. (2017).Malay Sign Language (MSL) for Beginner using android application. In Proceedings of the International Conference on Information Communication and Technology, Kuala Lumpur, Malaysia,

[16] Restituyo, C.A., Loizides F., Yang, S., Weir K., Worrallo, A., Hartley, T., Souleles, N., \& Loizou, M. Presenting and Investigating the Efficacy of an Educational Interactive Mobile Application for British Sign Language Using Hand Gesture Detection Techniques. In Proceedings of the 16th World Conference on Mobile and Contextual Learning, Larnaca, Cyprus, 30 October-1 November 2017.

[17] Khan, N.S., Abid, A., Abid, K., Farooq, U., Farooq, M.S., Jameel, H. Speak Pakistan(2015). Challenges in Developing Pakistan Sign Language using Information Technology. Int. J. South Asian Stud. 30, 367-379.

[18] Amit K. G. \& Ajay K. (2017). American Sign Language Recognition System Using Image: International Journal on Computer Science and Engineering (IJCSE). ISSN: 0975- $3397 \quad$ Vol.9 No.07 Jul 2017

[19] Punchimudiyanse, M. (2017). Animation of Finger spelled Words and Number Signs of the Sinhala Sign Language. ACM Trans. Asian-Low-Resour. Lang. Inf. Process. 2017, [CrossRef]

[20] Korte, J., Potter, L.E.,Nielsen, S.(2012). Designing a Mobile Video Game to Help Young Deaf Children Learn Auslan. In Proceedings of the BCS Human Computer Interaction Conference, Birmingham, UK, 10-14 September 2012; pp. 345-350.

[21] Lukka K. (2003). The Constructive Research Approach. Case study research in Turku School of Economics and Business Administration, pp.83-101

[22] Adekunle, O. (2011). The constructive research approach in project management Journal of Managing Projects in Business, Issue 4.

research.

International 